UCRL-JC-128614

PREPRINT

\title{
Optical Feedback Signal for Ultrashort Laser Pulse Ablation of Tissue
}

\author{
B.-M. Kim \\ M. D. Feit \\ A. M. Rubenchik \\ B. M. Mammini \\ L. B. Da Silva
}

This paper was prepared for submittal to the

Fourth Conference on Laser Ablation

Pacific Grove, CA

July 21-25, 1997

July 1, 1997

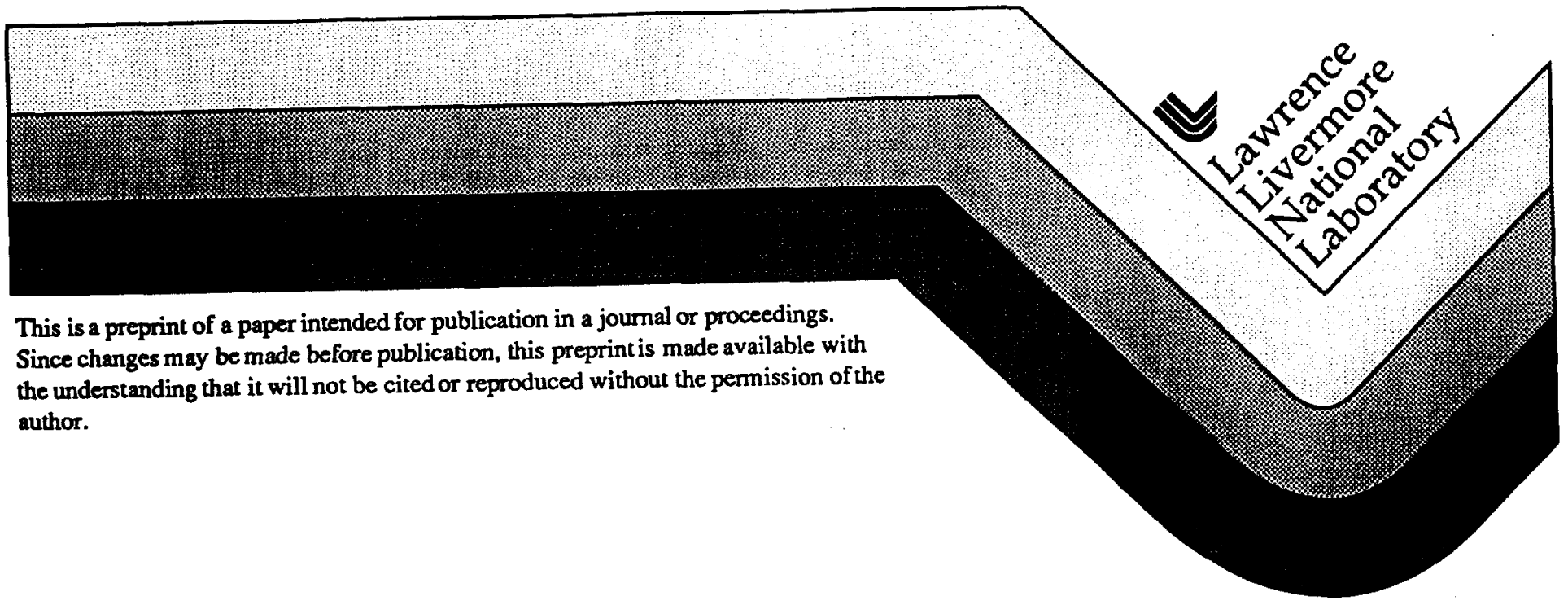




\section{DISCLAMMER}

This document was prepared as an account of work sponsored by an agency of the United States Government. Neither the United States Government nor the University of California nor any of their employees, makes any warranty, express or implied, or assumes any legal liability or responsibility for the accuracy, completeness, or usefulness of any information, apparatus, product, or process disclosed, or represents that its use would not infringe privately owned rights. Reference herein to any specific commercial product, process, or service by trade name, trademark, manufacturer, or otherwise, does not necessarily constitute or imply its endorsement, recommendation, or favoring by the United States Government or the University of California. The views and opinions of authors expressed herein do not necessarily state or reflect those of the United States Government or the University of Califomia, and shall not be used for advertising or product endorsement purposes. 


\title{
Optical Feedback Signal for Ultrashort Laser Pulse Ablation of Tissue
}

\author{
B.-M. Kim, M. D. Feit, A. M. Rubenchik, B. M. Mammini, L. B. Da Silva
}

\author{
Lawrence Livermore National Laboratory \\ PO Box 808, mail stop L-399 \\ Livermore, CA 94550 \\ (Phone) 510 - 423 - 3262 \\ (FAX) $510-424-2778$ \\ E-mail : kim12@llnl.gov
}

\begin{abstract}
An optical feedback system for controlled precise tissue ablation is discussed. Our setup includes an ultrashort pulse laser (USPL), and a diagnostic system utilizing analysis of either tissue fluorescence or plasma emission luminescence. Current research is focused on discriminating hard and soft tissues such as bone and spinal cord during spinal surgery using either technique. Our experimental observations exhibit considerable spectroscopic contrast between hard and soft tissue, and both techniques offer promise for a practical diagnostic system.
\end{abstract}

\section{Keywords}

Ultrashort pulse laser, tissue ablation, plasma luminescence, tissue fluorescence, optical feedback system

* Work performed at Lawrence Livermore National Laboratory under the auspices of the U.S. Department of Energy under contract No. W-7405-ENG-48. 


\section{Introduction}

Since the first use of lasers in the medical field, considerable effort has been made to replace conventional surgical tools with lasers. To be a practical alternative, clinical lasers have to be easy to control, safe, and effective in cutting and removing tissue with limited collateral damage. Ultrashort pulse lasers $(<1 \mathrm{psec})$ are of significant interest to clinicians and researchers due to precise and highly effective ablation capabilities $(\sim 1 \mu \mathrm{m} / \mathrm{pulse})$ accompanied by minimal collateral thermal/mechanical damage [1]-[5]. Thermal damage is minimized for two reasons. First, USPL has a high ablation efficiency, i.e. less energy is required per pulse compared to the nanosecond pulses. For example, the ablation threshold is less than $1 \mathrm{~J} / \mathrm{cm}^{2}$ for 0.35 psec pulses vs. $20 \mathrm{~J} / \mathrm{cm}^{2}$ for $1 \mathrm{~ns}$ pulses for tooth ablation [2]. Second, most of the energy that is deposited is taken away by the expanding plasma and ejected meterial. Mechanical damage is also not significant since due to the above reason and the short deposition time, the shockwave into the material experiences a rapid decay [6]. In Fig. 1, we show the results of drilling a human tooth with 350 fsec laser pulses [7]. The smooth ablation surface and absence of mechanical cracking is characteristic of USPL ablation. These characteristics of USPL tissue ablation led to its use in ophthalmology [8]-[11] and preliminary dental trials [4], [12]-[13] where precise ablation is needed. Additionally, it has potential for use in the areas of midear bone ablation, bone incision, microperforation etc. [2]. The present work focuses on the clinical application of bone ablation for spinal surgery.

An USPL operating at $1 \mathrm{kHz}$ will remove on the order of $1 \mathrm{~mm}$ of material per second. This makes an automatic feedback and control system necessary for microsurgical applications such as spinal surgery or angioplasty to prevent accidental ablation of surrounding tissue. Fluorescence [14], [15] and plasma luminescence [16]-[18] have been used for detection of calcified atherosclerotic plague with high sensitivity in angioplasty. A major drawback of using fluorescence spectroscopy is interference with blood clots and need for additional diagnostic light source [14], [17]. Plasma luminescence during pulsed 
laser ablation leads to a characteristic spectrum determined by tissue composition. A major disadvantage for longer pulse ablation system in using luminescence spectra in tissue diagnosis is that it requires an ablative laser fluence which might not be well-suited since it causes significant thermal/mechanical damage to the surrounding tissue. The present research is focused on fluorescence and luminescence spectral analysis to distinguish bone from soft tissue. We test the principle of using such spectra in real-time feedback signal during spinal surgery where the spinal cord must remain undamaged while bone is rapidly removed or drilled.

\section{Methods and Results}

A fresh piece of porcine spine was cut either axially or transversely to expose the spinal cord and bone cross sections. The cross sections were sprayed with saline occasionally to prevent dehydration. These tissues were irradiated by UV light generated by a tunable Optical Parametric Oscillator laser (Spectra Physics, Model \# 730) and the corresponding fluorescence was measured using a scanning double grating spectrometer with a photomultiplier tube (PMT). The PMT signal is gated and integrated during the fluorescence lifetime and multiple signals were accumulated at each wavelength. The whole sequence was computer controlled.

The excitation-emission matrix (EEM) measurement on bone and spinal cord was performed in the excitation range of 300 to $500 \mathrm{~nm}$. It was found that an excitation wavelength of $325 \mathrm{~nm}$ generates the most distinct spectra between the two types of tissue. Fig 2. shows the fluorescence spectra for the two tissues excited at $325 \mathrm{~nm}$. Both spectra were calibrated for the grating efficiency over wavelengths. The spinal cord displays fluorescence peaks at $395 \mathrm{~nm}$ and $465 \mathrm{~nm}$ while the bone fluorescence has a featureless spectrum with a wide plateau between $390 \mathrm{~nm}$ and $420 \mathrm{~nm}$. In this figure, the total magnitude of fluorescence is stronger with spinal cord than with bone. However, this overall magnitude can change dramatically depending upon slight changes in coupling 
efficiency between fluorescence source (tissue surface) and the detector. In a similar measurement not shown in this paper, the fluorescence intensity of bone was sometimes quite comparable with that of spinal cord. This observation implies that an absolute fluorescence intensity measurement can be misleading. It is desirable to have a different optical signature which will give us a more reliable contrast between the two tissues independent of the fluorescence intensity. One solution is to take the ratio of intensities at two different appropriately chosen wavelengths. Fig. 3 shows the fluorescence ratio between wavelengths of $395 \mathrm{~nm}$ and $495 \mathrm{~nm}$ for the two tissue types. The ratio is 0.79 for bone and 1.75 for spinal cord. Therefore, the fluorescence contrast ratio between the two tissues is about 2.2 and a two channel system with appropriate filters could be used for active laser control.

Our ultrashort pulse laser ablation system is equipped with four separate lasers. An $82 \mathrm{MHz}$ Ti-Sapphire actively mode-locked laser (Spectra Physics, Model \# 3960) is pumped by a $5 \mathrm{~W}$, frequency doubled Nd:YAG laser (Spectra Physics Model : Millenia) running at $532 \mathrm{~nm}$. The mode-locked laser pulse has duration of $100 \mathrm{fsec}$. Its power is, in turn, amplified by another Ti-Sapphire regenerative amplifier (Positive Light, Model : Spitfire) through a chirped pulse amplification (CPA) process. This amplifier is pumped by a $10 \mathrm{~W}, 527 \mathrm{~nm} \mathrm{Nd:YLF} \mathrm{laser} \mathrm{(Positive} \mathrm{Light,} \mathrm{Model} \mathrm{:} \mathrm{Merlyn).} \mathrm{The} \mathrm{final} \mathrm{pulse}$ duration is about $150 \mathrm{fsec}$ running at $1 \mathrm{kHz}$ and its amplified energy is more than 1 $\mathrm{mJ} /$ pulse.

These 150 fsec pulses were focused onto the tissue to generate the plasma luminescence. The luminescence signal was collected by a $1 \mathrm{~mm}$ diameter optical fiber and was delivered to the spectrometer and charged coupled device (CCD) camera. The source light was normally incident onto the tissue and the fiber was placed $20^{\circ}$ from the normal direction and $5 \mathrm{~mm}$ away from the tissue surface. The source light shutter and CCD shutter were controlled by a pulse generator. 
Typical plasma luminescence signals for bone and spinal cord are shown in Fig. 4. The tissues were irradiated by $150 \mathrm{fsec}, 1 \mathrm{~mJ}$ pulses running at $1 \mathrm{kHz}$ and the luminescence was recorded by spectrometer and $\mathrm{CCD}$ for $1 \mathrm{sec}$. The bone luminescence spectrum displays many strong $\mathrm{Ca}$ lines with some $\mathrm{Na}, \mathrm{Mg}$, and $\mathrm{P}$ lines. The strongest peak appears near $615 \mathrm{~nm}$ where several $\mathrm{Ca}$ lines are close together. On the other hand, the spinal cord luminescence spectrum contains a $\mathrm{Na}$ line at $589 \mathrm{~nm}$ with no noticeably strong lines elsewhere. For a similar reason as in the fluorescence case, it is desirable to take an intensity ratio between two wavelengths to discriminate between the tissue types. The intensity ratio at $615 \mathrm{~nm}$ and $575 \mathrm{~nm}$ is approximately 6 for bone and 1.5 for spinal cord thus producing a contrast ratio of 4 for these tissues.

It remains to be shown that one can discriminate bone and spinal cord over a wide intensity range of luminescence. Fig. 5 shows the temporal changes of the averaged luminescence signal for every 0.1 second since the onset of the laser irradiation. Again, the laser was running at $1 \mathrm{kHz}$. Therefore, each datum corresponds to the averaged luminescence over 100 shots. The bone luminescence diminishes exponentially with time as the ablation front propagates through the tissue. This observation presumably results from the decreasing amount of material ejected as the laser drills a hole into the tissue as shown in Fig. 1. Furthermore, the distance between the ablation front and the detector becomes larger as the hole becomes deeper. However, as shown in Fig. 6, the ratio between two wavelengths ( 615 and $575 \mathrm{~nm}$ ) is still stable for bone and spinal cord regardless of the intensity of luminescence. The spinal cord luminescence does not seem to decrease with time supposedly because this soft tissue moves due to shockwave during ablation resulting in multiple ablation spot. The ratio for bone is 4.8 which is about 3.4 times stronger that that of spinal cord which is only 1.4. 


\section{Discussion}

One of the major advantages of using fluorescence spectra in feedback control is that one can determine the tissue type before ablating the tissue. On the other hand, for luminescence feedback it is necessary to ablate a small amount of tissue. However, the luminescence spectroscopy technique does not need an additional light source which is required for fluorescence analysis. The requirement of inducing ablation to perform luminescence spectroscopy can probably be acceptable since most tissues can tolerate microns of ablation. Therefore, if the tissue can be discriminated within approximately 10 microns (i.e. about 10 pulses), serious damage to the tissue can be avoided.

We have shown that both tissue fluorescence and luminescence spectra can be effectively used to discriminate between hard and soft tissues. The contrast ratio between bone and spinal cord was 2.2 with the fluorescence technique and 3.4 - 4 with the plasma luminescence technique. Ultimately, by setting an appropriate threshold ratio between bone and spinal cord signals, we can create an effective on/off feedback control.

From Fig. 4, one might conclude that overall intensity of luminescence would provide a better signature to discriminate the tissue types since the intensity of bone luminescence is much greater that that of spinal cord luminescence. However, as demonstrated in Fig. 5, luminescence intensity decreases exponentially as ablation proceeds and after 0.5 second, the overall bone luminescence intensity becomes comparable with the spinal cord intensity (Fig. 5). Additionally, the luminescence signal collection efficiency can vary significantly depending upon the detector position during a clinical procedure. Therefore, a relative measurement is more reliable. By taking the ratio between two different wavelengths, a highly stable signal is found despite variations in the detection efficiency.

We found that plasma luminescence spectroscopy generates better contrast between bone and spinal cord. Furthermore, it was shown that luminescence can be measured very consistently over a wide range of the absolute intensity. With fluorescence, it might be 
difficult to deliver the excitation beam and collect a good fluorescence signal from the ablation front because the hole diameter decreases as ablation proceeds as shown in Fig. 1. Luminescence spectroscopy does not have this problem because the luminescence is collected from the ejected plume. Therefore, a feedback system utilizing luminescence appears preferable.

\section{Summary and Future Studies}

Tissue fluorescence and plasma luminescence of bone and spinal cord were investigated as the basis for a real-time optical feedback system. The intensity ratio between two different wavelengths produces a contrast ratio of 2.2 with fluorescence and 3.4 with luminescence for hard and soft tissues. The luminescence spectral analysis is preferable because it generates a better contrast for the two tissue types, and produces more stable results regardless of luminescence intensity.

A real-time controlled ultrashort pulse laser ablation system is now being assembled and an appropriate delivery system is also under investigation. 


\section{References}

[1] B. C. Stuart, M. D. Feit, S. Herman, A. M. Rubenchik, B. W. Shore, and M. D. Perry, "Nanosecond-to-femtosecond laser-induced breakdown in dielectrics," Physical Review, vol. 53, no. 4, 1996, pp. 1749-1761.

[2] J. Neev, L. B. Da Silva, M. D. Feit, M. D. Perry, A. M. Rubenchik, and B. C. Stuart, "Ultrashort pulse lasers for hard tissue ablation," IEEE J. Selected Topics in Quantum Electronics, vol. 2, no. 4, 1996, pp. 790-800.

[3] A. A. Oraevsky, L. B. Da Silva, A. M. Rubenchik, M. D. Feit, M. E. Glinsky, M. D. Perry, B. M. Mammini, W. Small, and B. C. Stuart, "Plasma mediated ablation of biological tissues with nanosecond-to-femtosecond laser pulses: Relative role of linear and nonlinear absorption," IEEE J. Selected Topics in Quantum Electronics, vol. 2, no. 4, 1996, pp. 801-809.

[4] L. B. Da Silva, B. C. Stuart, P. M. Celliers, T. D. Chang, M. D. Feit, M. E. Glinsky, N. J. Heredia, S. Herman, S. M. Lane, R. A. London, D. L. Mattews, j. Neev, M. D. Perry, and A. M. Rubenchik, "Comparison of soft and hard tissue ablation with sub-ps and ns pulse lasers," SPIE Proceedings, vol. 2681, 1996, pp. 196-200.

[5] M. D. Feit, A. M. Rubenchik, and B. W. Shore, "Unique aspects of laser energy deposition in the fs pulse regime," SPIE Proceedings, vol. 2672, 1996, pp. 243-249.

[6] M. D. Feit, A. M. Rubenchik, B.-M. Kim, L. B. Da Silva, M. D. Perry, "Physical characterization of ultrashort laser pulse drilling of biological tissue," (COLA'97 conference paper).

[7] B.C. Stuart, M.D. Perry, M.D. Feit, L.B. Da Silva, A.M. Rubenchik, and J. Neev, "Machining of biological materials, dielectrics and metals with femtosecond lasers", OSA Topics in Optical Science : Lasers and Optics for Manufacturing, vol. 9, 1996, pp. 94-98.

[8] R. Birngruber, C. A. Puloafito, A. Gawande, W.-Z. Lin, R. T. Schoenlein, and J. G. Fujimoto, "Femtosecond laser-tissue interaction: Retinal injury studies," IEEE J. Quantum Electronics, vol. QE-23, no. 10, 1987, pp. 1836, 1844.

[9] T. Juhasz, X. H. Hu, L. Turi, and Z Bor, "Dynamics of shockwaves and cavitations generated by picosecond laser pulses in corneal tissue and water," Lasers Surg. Med., vol. 15, 1994, pp. 91-98.

[10] T. Juhasz, G. A. Kastis, C. Suárez, L. Turi, Z. Bor, W. E. Bron, "Shockwave and cavitation bubble dynamics during photodisruption in occular media and their dependence on the pulse duration," SPIE Proceedings, vol. 2681, 1996, pp. 428-436.

[11] T. Juhasz, G. A. Kastis, C. Suárez, Z. Bor, and W. E. Bron, "Time-resolved observations of shockwaves and cavitation bubbles generated by femtosecond laser pulses in corneal tissue and water," Lasers Surg. Med., vol. 19, 1996, pp. 23-31.

[12] J. Neev, D. S. Huynh, W. A. Carrasco, P. Wilder-Smith, L. B. Da Silva, M. D. Feit, M. D. Perry, A. M. Rubenchik, and B. C. Stuart, "Thermal and noise level characteristics of hard dental tissue ablation with 350 fs pulse laser," SPIE Proceedings, vol. 2672, 1996, pp. 262-270. 
[13] A. M. Rubenchik, L. B. Da Silva, M. D. Feit, S. M. Lane, R. A. London, M. D. Perry, and B. C. Stuart, "Dental tissue processing with ultra-short pulse laser," SPIE Proceedings, vol. 2672, 1996, pp. 222-230.

[14] A. J. Morguet, B. Körber, B. Abel, H. Hippier, V. Wiegand, and H. Kreuzer, "Autofluorescence spectroscopy using a $\mathrm{XeCl}$ Excimer laser system for simultaneous plaque ablation and fluorescence excitation," Laser Surg. Med., vol. 14, 1994, pp. 238-248.

[15] T. F. Garrand, M. L. Stetz, K. M. O'Brien, G. R. Gindi, B. E. Sumpio, and L. I. Deckelbaum, "Design and evaluation of a fiberoptic fluorescence guided laser recanalization system," Lasers Surg. Med., vol. 11, 1991, pp. 106-116.

[16] A. A. Oraevsky, S. L. Jacques, G. H. Pettit, F. K. Tittle, and P. D. Henry, "XeCl laser ablation of atherosclerotic aorta," Lasers Surg. Med., vol. 13, 1993, pp. 168178.

[17] L. I. Deckelbaum, J. J. Scott, M. L. Stetz, K. M. O'Brien, and G. Backer, "Detection of calcified atherosclerotic plaque by laser-induced plasma emission," Lasers Surg. Med., vol. 12, 1992, pp. 18-24.

[18] A. A. Oraevsky, R. O. Esenaliev, and V. S. Letokhov, "Temporal characteristics and mechanism of atherosclerotic tissue ablation by nanosecond and picosecond laser pulses," Lasers in the Life Sciences, vol. 5, 1992, pp. 75-93. 


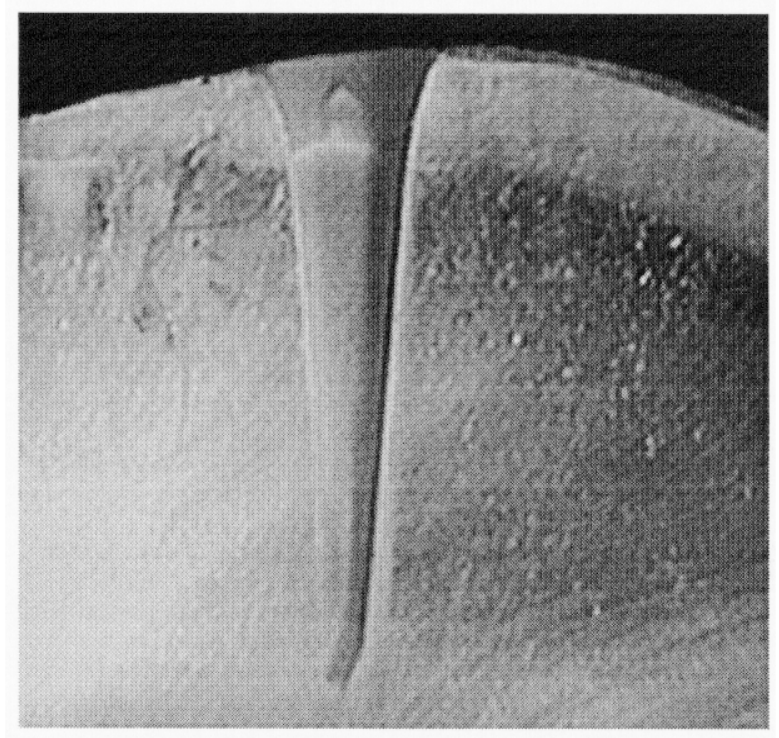

Fig. 1. Cross section of a conical hole drilled in tooth by 350 fsec laser system. With no thermal shock, there is no collateral damage to adjacent tissue. 


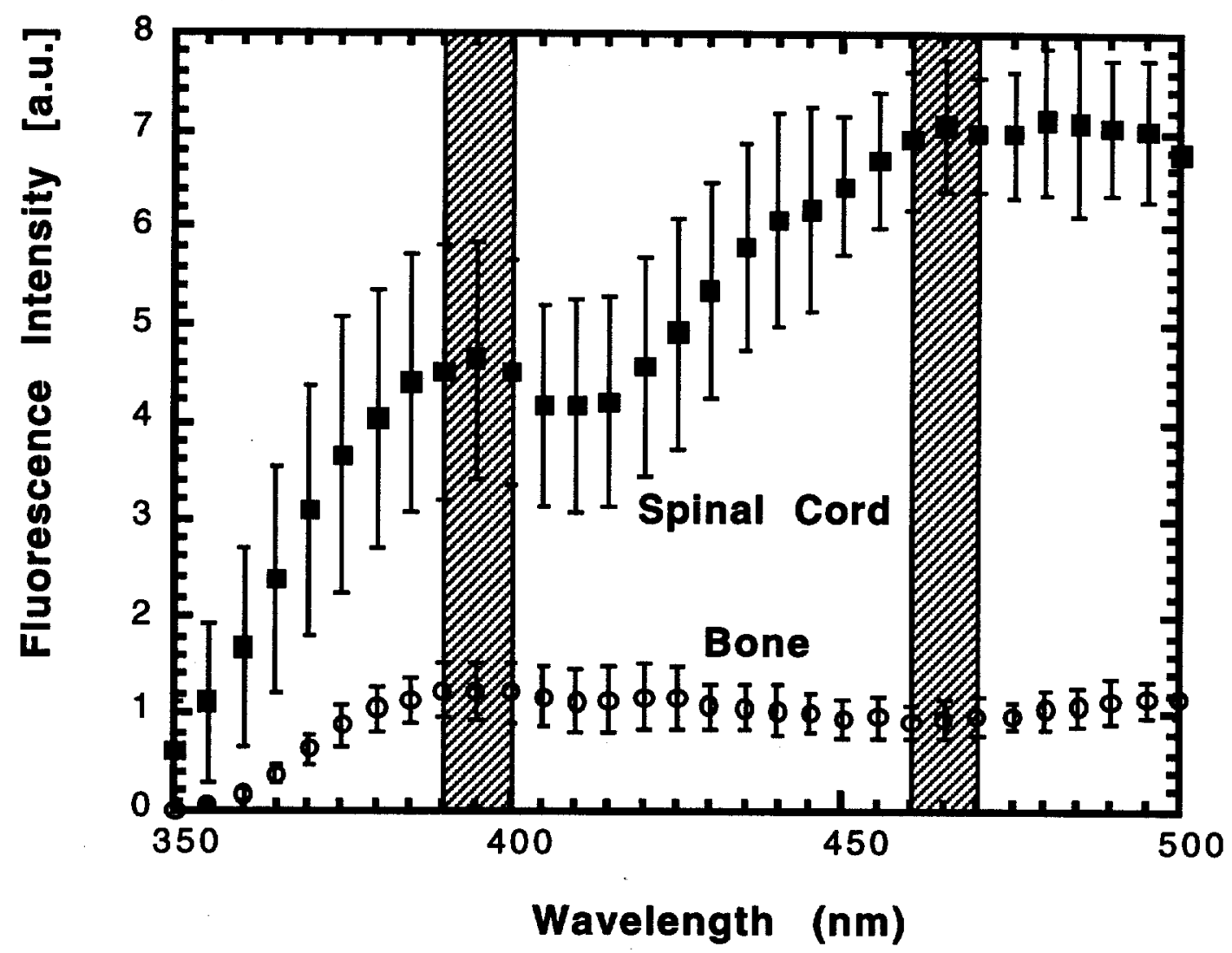

Fig. 2. Fluorescence spectra for bone and spinal cord. The spinal cord displays fluorescence peaks at $395 \mathrm{~nm}$ and $465 \mathrm{~nm}$ while the bone fluorescence has relatively monotonous spectrum with wide plateau between $390 \mathrm{~nm}$ and $420 \mathrm{~nm}$. 


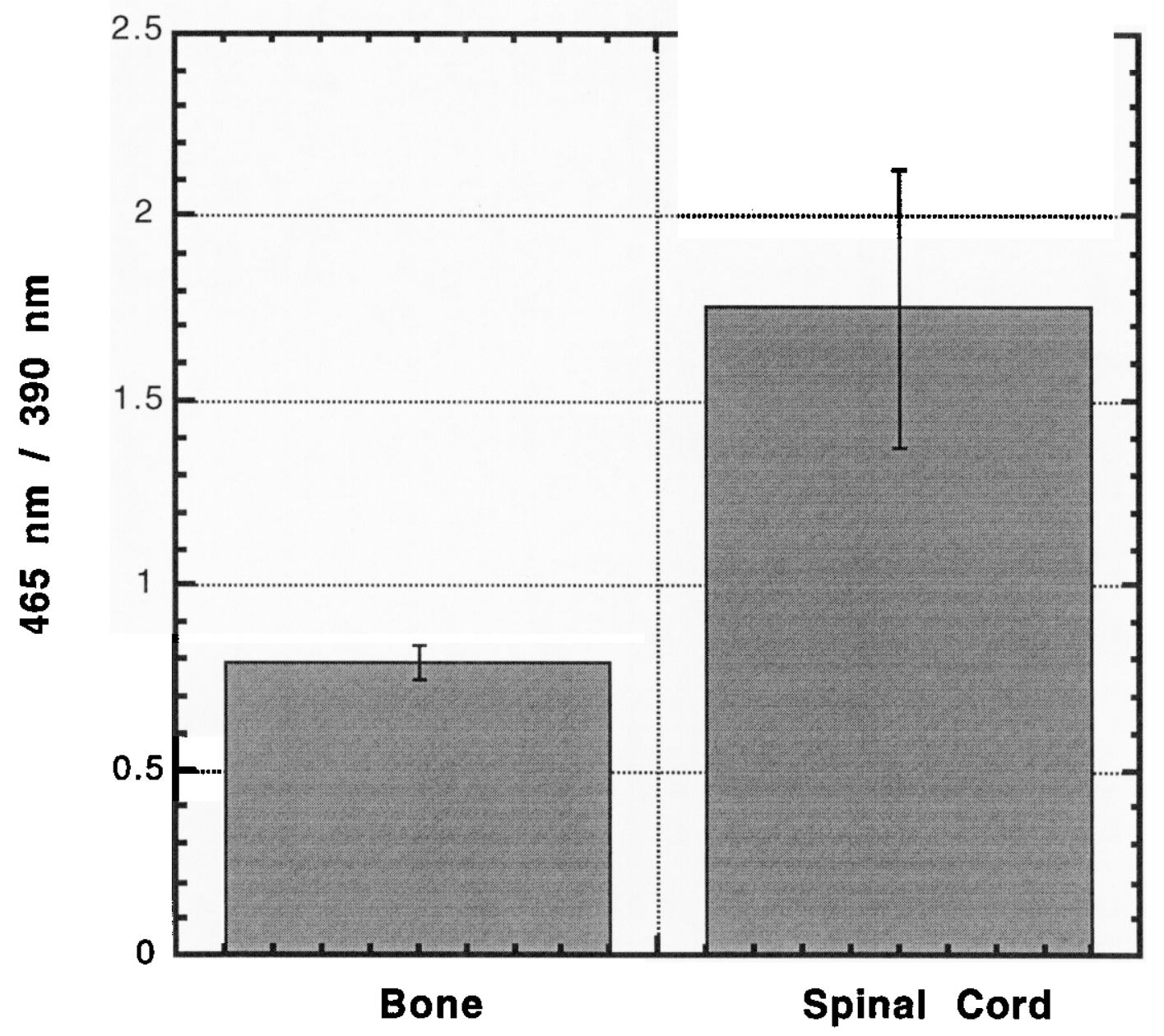

Fig. 3. Ratio $465 \mathrm{~nm} / 390 \mathrm{~nm}$ is 0.79 for bone and 1.75 for spinal cord. Laser will be automatically turned off if the ratio for bone rises above a threshold of $1-1.3$. 


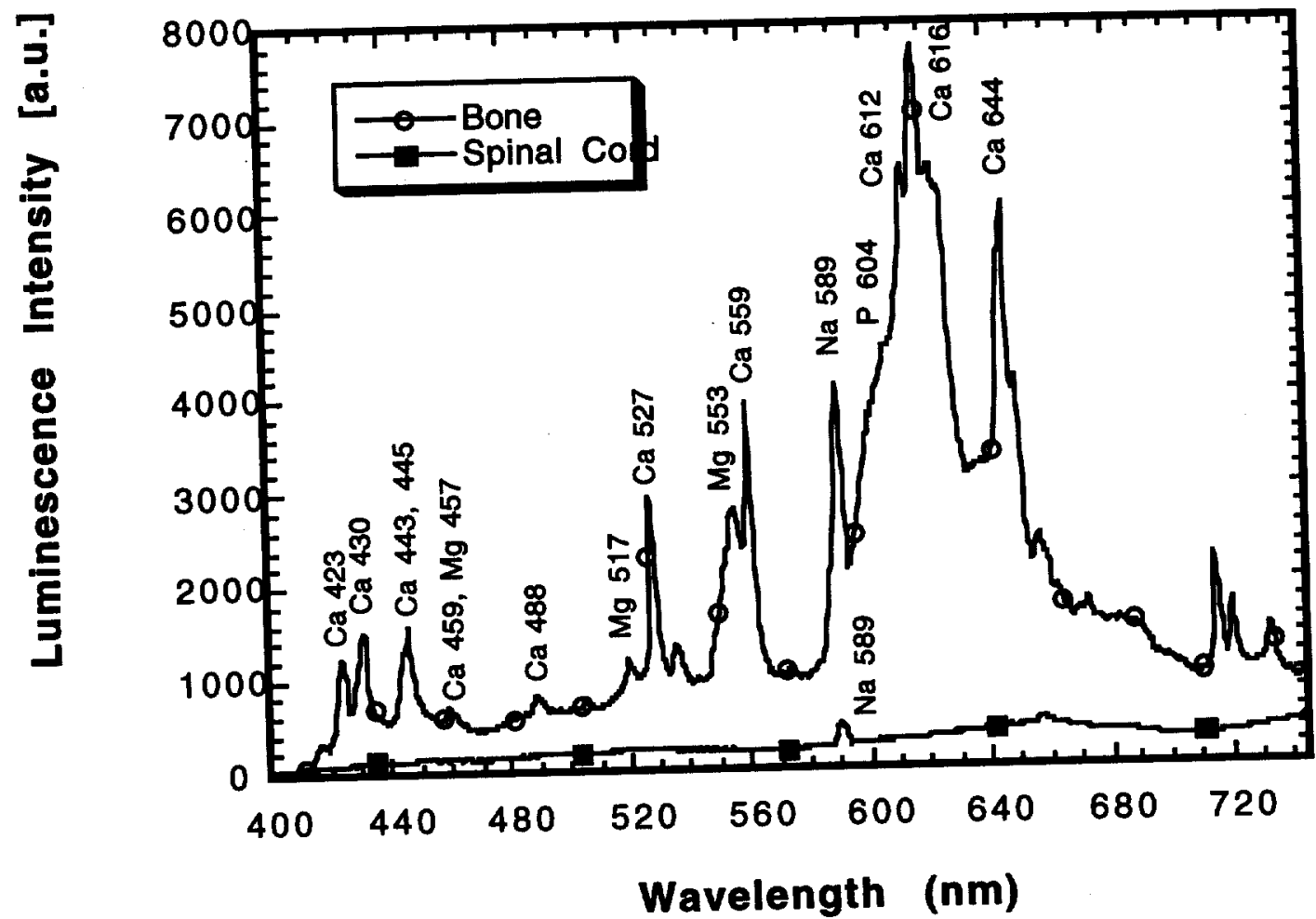

Fig. 4. Plasma luminescence spectra of bone and spinal cord. Strong $\mathrm{Ca}$ lines are shown in the visible range. By measuring $\mathrm{S}_{615} / \mathrm{S}_{575}$, we will be able to discriminate between bone and spinal cord. 


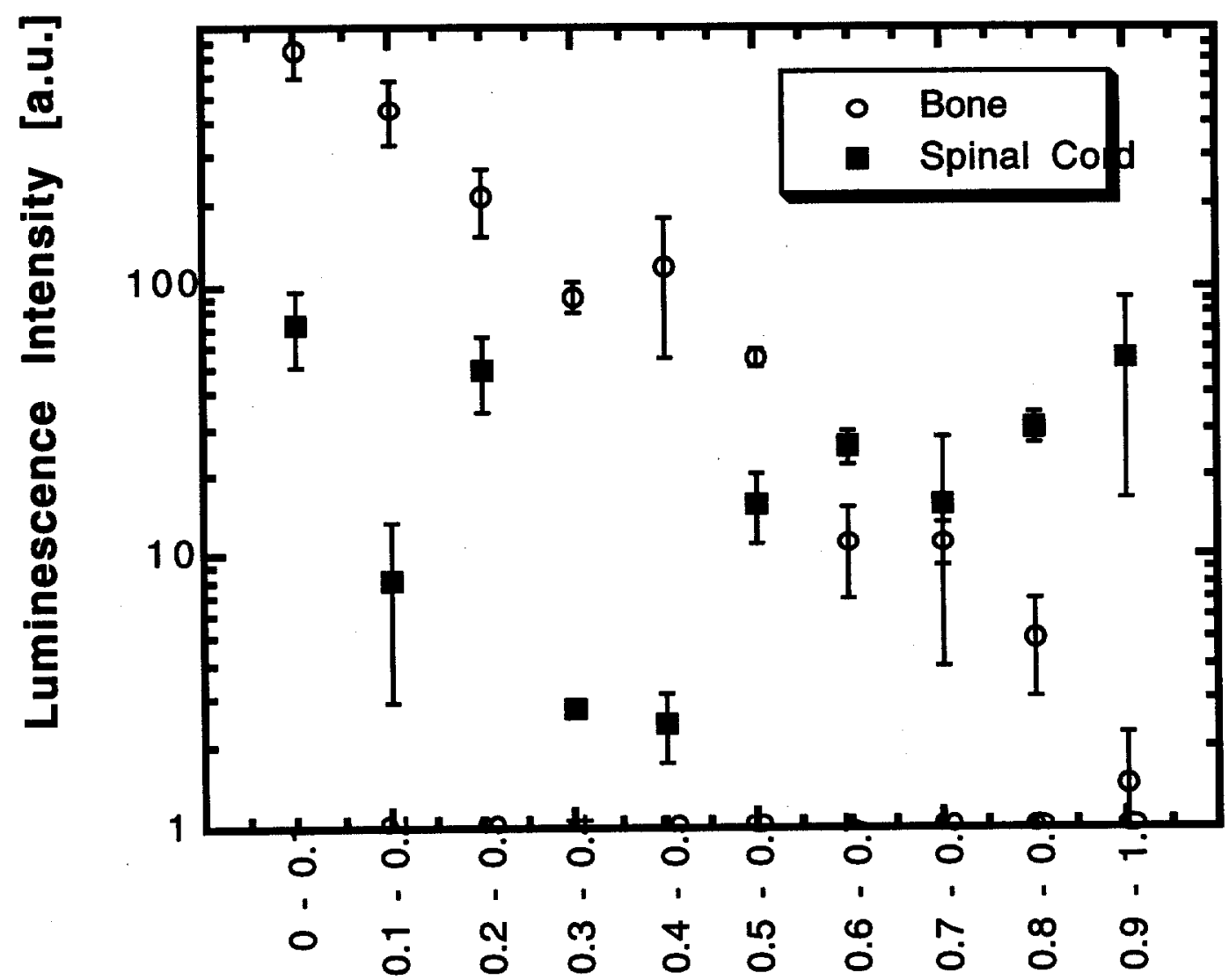

\section{Interval (sec)}

Fig. 5. While Drilling a Hole, the Luminescence Signal Becomes Weaker because Less material is ablated as the hole becomes deeper. Each value includes averaged luminescence signal over 100 shots (Total \# of shots $=1000$ ). Rep rate $=1 \mathrm{kHz}$. 


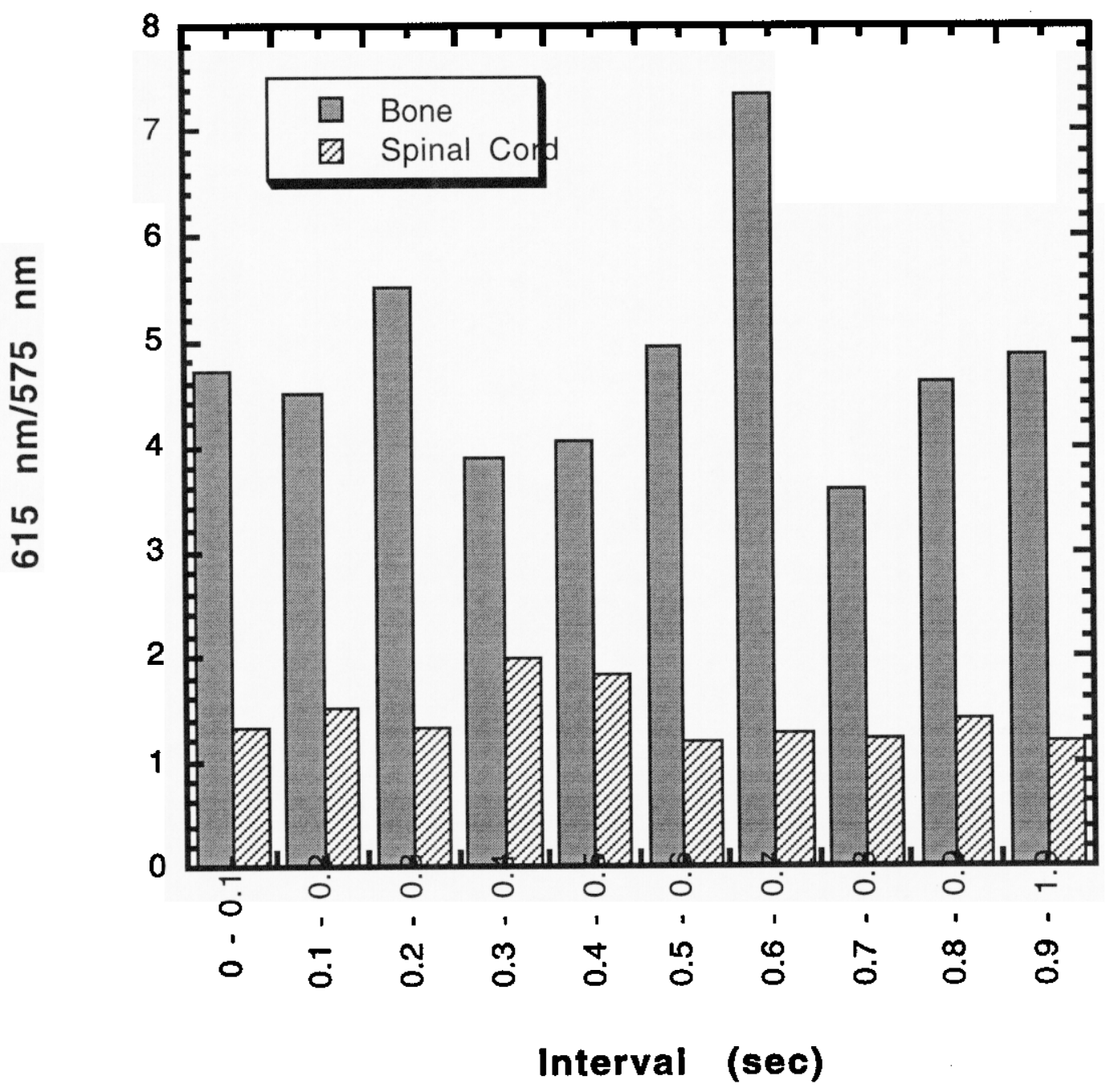

Fig. 6. Average wavelength ratio $(615 \mathrm{~nm} / 575 \mathrm{~nm})$ is 4.8 for bone and 1.4 for Spinal Cord. The ratio is consistent regardless of the luminescence intensity. By setting the threshold ratio at $2.5-3$, we can create the on/off feedback control 


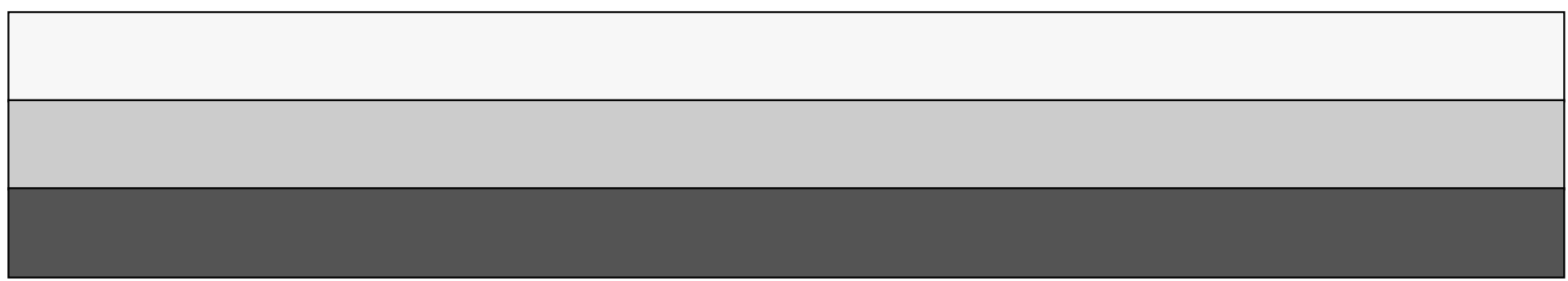

